\title{
LA TEORÍA TEXTUAL BARTHESIANA: EL TEXTO COMO SEMIOSIS*
}

\author{
Juan Luis Jiménez Ruiz
}

\author{
Universidad de Alicante
}

La consideración de la importancia de las manifestaciones humanas en cuanto expresión linguística ha llevado al lenguaje al abandono de la mera faceta objetiva (filología ad usum) y a la construcción de la faceta sujetual -lingüística del sujeto- (Jiménez Ruiz, 1994a) que, a la larga, le ha permitido la adquisición del verdadero rango de modelo puro del espíritu, auténtico configurador de los discursos sobre la literatura.

Ello entraña, obviamente, un proceso de revisión epistemológica que, sin llegar a asumir el rango de ruptura, en sentido bachelardiano (1973) - puesto que, aunque muchos lo hayan deseado, no se ha realizado la ansiada mutación conceptual - , ha producido el estadio de transformación epistémica que ha sumido al lingüista en la duda de la adopción entre un formalismo inmanentista, que separa el signo de la

* A propósito de A. Sirvent Ramos, La teoría textual barthesiana, Murcia: Universidad de Murcia, 1992, 194 págs. 
cosa y lo pone en relación con otros signos en un sistema lógico cerrado, y una actitud más trascendental, que une el signo con la realidad, propiciando una apertura del sistema y, consecuentemente, la concepción de la actividad lingüístico-literaria como un auténtico sistema ideológico capaz de sintetizar las posturas objetivistas y subjetivistas (Bakthine, Bourdieu), formalista y pragmática (van Dijk), interna y externa (Weinreich).

Y si, además, asistimos hoy en día a un momento en el que no sólo triunfa el pragmatismo realista que considera la validez operatoria en términos de verdad o falsedad -muy propio de los dominios científicos- y no en términos de corrección o incorrección, como corresponde al ámbito epistemológico, sino que también se considera inútil e inadecuado todo debate ideológico sobre el papel de la lengua en la sociedad (Villena, 1993), la figura, la obra y, en general, el pensamiento sobre la literatura de $\mathrm{R}$. Barthes pueden parecer a primera vista reducidos a un segundo plano, máxime cuando las categorías literarias barthesianas se han modificado a lo largo de su obra, y el juego de palabras y de los diferentes sentidos de un término han podido sumir al lector en la incomprensión y, en el mejor de los casos, en la perplejidad.

Sin embargo, la importancia de las manifestaciones humanas en cuanto expresión lingüística - que nadie pone en duda - ha tenido el acierto de exigir la recuperación de los planteamientos kantianos relativos a la consideración de que la forma predomina en la obra, la forma en cuanto lenguaje independiente de lo sensible y del contenido, a la espera sólo del ejercicio hermenéutico sistemático que plasme lo diverso en un todo armonizador (Dilthey, 1978: 22) y posibilite la auténtica historia de las formas significantes (las poéticas, los códigos narrativos y lo que él denomina escritura: ecuación personal a partir de la lengua y las convenciones literarias); aunque también ha tenido el inconveniente de aportar como respuesta epistémica no sólo erróneas equiparaciones entre el objeto real (la literatura) y el pensamiento, sino también confusiones entre el texto literario (plano literario) y el ensayo sobre el texto literario (plano metaliterario), con lo que esto ha supuesto desde el punto de vista epistemológico, puesto que la literatura no es ni un concepto producido ni un objeto real, sino el objeto ideológico que se constituye como tal gracias al discurso glotológico que toma por objeto la producción literaria (Sallenave et alii, 1981).

Lo importante de todo ello, lejos de excesivos formalismos de pretendido cientificismo metodológico, ha sido la confirmación de la prioridad de la tesis del primado del ser sobre el pensamiento, que ha 
evitado la vuelta al idealismo y ha potenciado la necesidad de reflexionar sobre el hecho literario mismo, para que la enajenación más profunda del sujeto de la civilización científica, que pierde su sentido en las objetivaciones del discurso (el «esto soy» ha sido invertido en el «soy yo») y que participa al mismo tiempo y contradictoriamente en el hedonismo profundo de toda cultura y en su propia destrucción (Barthes, 1973: 23), pueda adquirir su lugar adecuado en el ámbito de las disciplinas humanas en cuanto discursos del sujeto (Lacan, 1966: 59 y ss.).

Por eso, las obras de los sujetos no pueden explicarse exclusivamente desde un método científico-objetivo sino desde un enfoque hermenéutico (Jiménez Ruiz, 1994c), desde una hermenéutica semiótica en cuanto teoría generalizada de la interpretación signológica (Ortiz Osés, 1976: 66) que nos permita integrar «explicación» y «comprensión» (Mardones, 1991; Wright, 1971), alterando el centro de atención desde el objeto hacia el sujeto, desde la obra en cuanto hecho objetivo y cerrado al texto en cuanto dimensión literaria y retórica, en cuanto reencuentro y transformación de la literatura en escritura, instaurando así el paso de la objetividad científica (Hjelmslev, 1943: 20-21; Chomsky, 1965: 5-60) a la nueva retórica literaria (Barthes et alii, 1966; Herrero, 1986) gracias al trabajo crítico, hermenéutico y «deconstructor» (Beorlegui, 1993: 71-72), en suma, gracias a la lectura en cuanto «reescritura» (Vera Luján, 1975: 328).

Y eso es, precisamente, lo que realiza la profesora Sirvent en La teoría textual barthesiana, una lectura no literal -hermenéutica- que, a través del juego de los significantes, ofrezca una línea de comprensión que rompa el hermetismo con el que algunos catalogan la obra de Barthes.

En este sentido, va a dar forma de manera clara y estructurada al modelo textual analítico barthesiano. Para ello, realiza, en primer lugar, un análisis de las diferentes categorías literarias; a saber, la evolución de la concepción clásica de la literatura a la moderna concepción del texto (cap. I), la evolución del escritor desde el compromiso con el contenido de la obra hacia el compromiso desde una perspectiva formal (cap. II), las diferentes escrituras, las condiciones del empleo 
del término escritura y sus diferencias con el estilo (cap. III), y, finalmente, el proceso de lectura en tanto que productividad, distinguida de la crítica y enriquecida con el psicoanálisis lacaniano (cap. IV); y, en segundo lugar, un estudio del texto como tal, es decir, del proceso de la significación y de las diferentes tipologías textuales propuestas por Barthes (cap. V).

Como ocurre en cualquier ámbito disciplinario en el que se haya producido una ampliación objetual como la que hemos descrito, se hace necesario, a su vez, la autonomía epistémica - puesto que, en el caso presente, la variable kantiana, recogida por los planteamientos barthesianos (consciente o inconscientemente), no puede ser (y, de hecho, no lo es) una ampliación de una concepción sobre el mundo sino, más bien, una interrogación sobre el lenguaje -escritura-(Barthes, 1966: 43).

Ello justifica que, junto a la formulación de un aparato teórico (modélico, desde nuestra perspectiva sujetual) como un saber organizado sobre la literatura, la definición de este nuevo objeto de estudio e investigación, despojado de sus condicionamientos externos, psicológicos y sociales y asumido en tanto que escritura, sea la herencia positivista más palpable en la obra de Barthes.

De ahí la necesidad de comenzar las reflexiones del libro con un esbozo de la historia de este nuevo objeto (literatura en tanto que escritura) desde la perspectiva barthesiana (cap. I). Tras realizar un recorrido desde la literatura francesa clásica hasta la del siglo XIX, estudiando el mito del realismo y el de la separación entre prosa y poesía, Sirvent se detiene en la renovación literaria que se produce en la segunda mitad del siglo XIX, cuando

«[...] la literatura comienza a ser entendida como problemática de la forma y no como vehículo instrumental al modo en que lo había sido en la época clásica» (pág. 21).

Esta ampliación objetual es la que justifica una nueva historia de la literatura, una historia no ya de autores y de obras sino del ser literario 
(Jiménez Ruiz, 1988-89: 21-36), de la idea misma de la literatura. De hecho, frente a la historia externa, por ejemplo, que no ve en la literatura más que un hecho cultural, una sobreestructura susceptible de ser explicada por una infraestructura (sociológica, económica, etc.), un síntoma de una realidad más profunda a la que simultáneamente cubre y manifiesta; o a la historia crítica que, aunque busca las fuentes e influencias ejercidas por los sistemas literarios antecedentes, acaba en un proceso de desmembración del sistema literario, con el que se pierde la unidad de intensidad, la intuición estructural del conjunto de cada sistema; la historia del lenguaje en tanto que historia de los signos de la literatura permite al estudioso trascender la mera faceta crítica e ir más allá, oponiendo al movimiento centrífugo del análisis crítico el movimiento centrípeto que le conducirá a la intuición estructural central y unificadora de cada sistema, sin ignorar: $1^{\circ}$ ) que sólo desde la totalidad del proceso histórico tienen sentido las diversas partes del mismo (Hegel, 1983: 225-226); $2^{\circ}$ ) que cada momento de la historia está generado por el anterior y es regenerador del siguiente; y $3^{\circ}$ ) que este proceso actúa por oposiciones en la que los sistemas literarios no son destruidos sino superados por los siguientes.

Se trata, consecuentemente, de una historia lineal de las técnicas semánticas gracias a las cuales la literatura se interroga sobre el mundo y sobre el propio lenguaje, en el primero de los casos, abarcando en su seno multiplicidad de saberes, que la configuran como mathesis, y, en el segundo, concretando estos saberes como un «saber de los signos» - semiosis - (Foucault, 1966: 77 y ss.), no presentando un contenido sino sugiriendo diferentes sentidos - literal y no literal, denotativo y emotivo (Jiménez Ruiz, 1992) - y, en definitiva, convirtiéndose en «escritura».

Consecuentemente, la escritura (cap. III) surge como «superación del reduccionismo que suponía la literatura tradicional» (pág. 67) y se produce cuando el escritor reflexiona y cuestiona el instrumento que utiliza, observa su trascendencia y el uso social de su forma. Se trata, obviamente, de la dimensión social de la escritura (que separa a Barthes de las corrientes más estrechamente formalistas del estructuralismo francés), muy diferente a la realidad individual del estilo. 
Como tuvimos ocasión de explicar recientemente (Jiménez Ruiz, 1994b), el paralelismo con el ámbito lingüístico es verdaderamente importante, puesto que se trata de la conexión ontológica (Lledó, 1970: 93 y ss.) de dos versiones distintas pero complementarias de un mismo lenguaje sujeto; a saber, la más empírica —lingüística- (Bakthine, 1929: 71-141; Villena, 1992: 37 y ss.; etc.) en la que el lenguaje sujeto necesita la materialización en la lengua y en el habla objetos (Crespillo, 1986: 15-25) —de hecho, la lingüística muestra que la enunciación es un proceso vacío que funciona a la perfección sin que sea necesario rellenarlo con las personas de sus interlocutores, puesto que el lenguaje conoce un «sujeto", no una persona (Barthes, 1984: 68)—; y, por otro lado, la versión más trascendental - literaria- (Derrida, 1971: 37 y ss.; Kristeva, 1971: 3-13), en la que el lenguaje sujeto, transformado por su destino social, se actualiza en la lengua y el estilo objetos, gracias a la función de la escritura, que lo correlaciona socialmente y lo individualiza en el acto de creación artística (Barthes, 1972: 24). Confróntese el esquema que aparece a continuación:

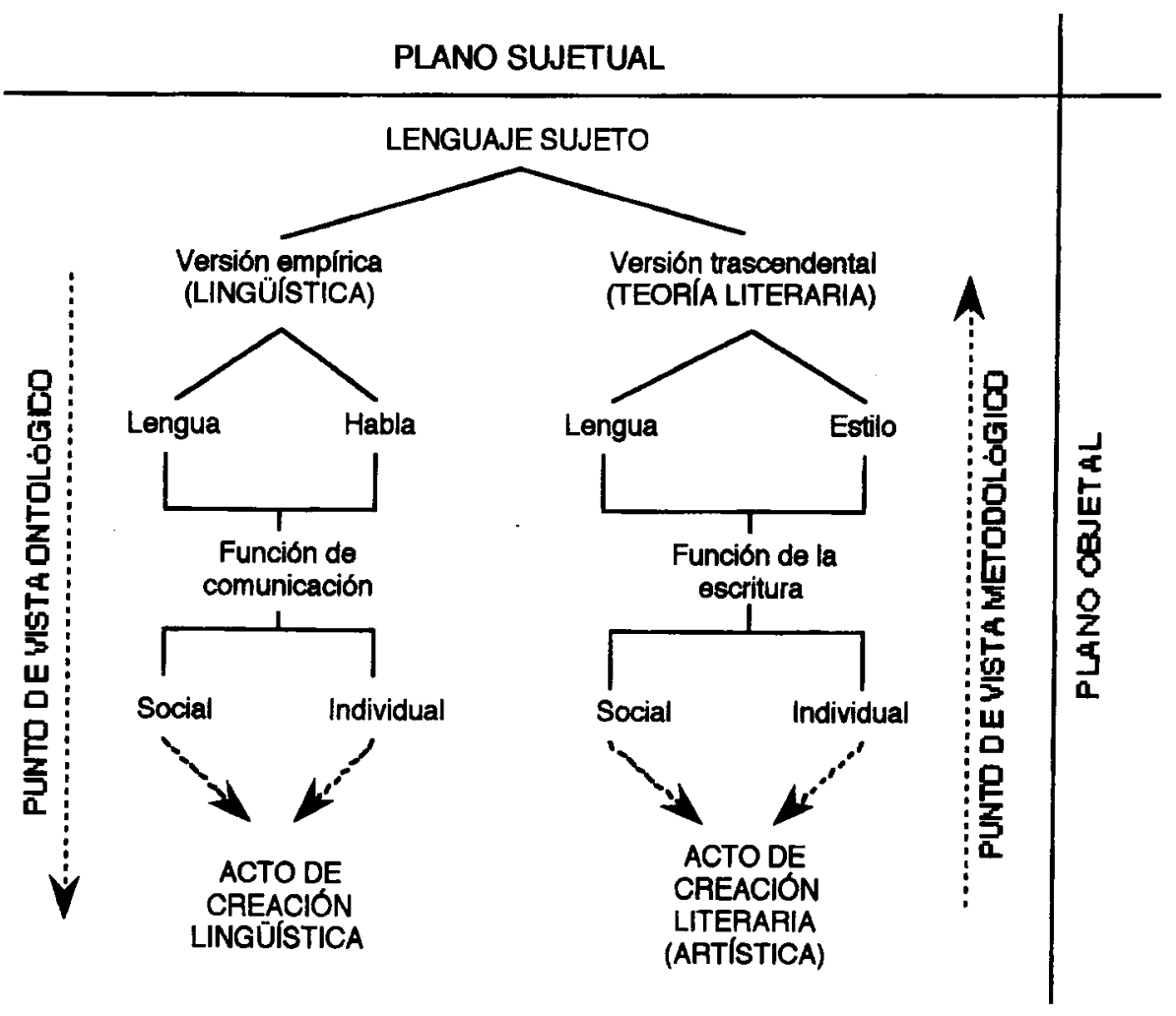


Y, precisamente, lo que desde un punto de vista ontológico constituye la instauración substancial de la Forma, desde un punto de vista metodológico se transforma en la búsqueda imposible de un lenguaje que no existe y que sólo puede liberarse en su grado cero. Como manifiesta explícitamente la profesora Sirvent:

«Llegamos así a una de las características fundamentales de la escritura: «el deseo del lenguaje, el placer del lenguaje» (pág. 90).

Uno de los requisitos para encontrar en la escritura el placer mencionado es que ésta sea plural, lo que justifica la aceptación en su seno del juego de la intertextualidad y de las nuevas orientaciones del psicoanálisis lacaniano. Con ello, el inmanentismo estructuralista, útil en sus primeros momentos, en tanto que reacción a la crítica tradicional, que consideraba al autor como causa de la obra, viene a completarse con esta actitud más humanista, que convierte al autor en fragmento de un código, en un sujeto disperso en el texto, que dialoga consigo mismo a través de la objetividad que ha quedado presente en la escritura (Lledó, 1991: pág. 78), a la espera sólo de la formulación explícita (teoría textual y psicoanálisis) que le otorgue su lugar. Se trata, pues, no de un mero descubrimiento (como pensaba Gadamer) ni de un mero acuerdo (como afirmaban los teóricos escolásticos), sino de un consentimiento y no de un mero convenio (positivismo).

En este sentido, el proceso de lectura y, consecuentemente, la figura del lector (cap. IV) cobran una gran importancia en la teoría textual barthesiana, puesto que, como reconoce A. Sirvent:

«Una de las mayores aportaciones de Barthes en lo que respecta a la lectura consiste en convertir al lector en un ser activo, inmerso, al igual que el escritor, en la productividad del texto» (pp. 110-111).

De ello se deduce una pluralidad de lecturas que no son anárquicas, puesto que parten del texto y se desprenden del texto mismo. Sin 
embargo, un término puede hablar de forma distinta a distintos lectores e incluso a un mismo lector en diferentes momentos. Es la libertad del significante con la que se amplían los horizontes de la lectura «pluri-isotópica» aludida por Greimas (1970: 188) para los textos no poéticos.

De ahí que se rompa con el efecto especular del predominio lingüístico (Crespillo, 1981: 25-31), que considera la literatura como un fenómeno comunicativo, y se pase a una concepción de la obra como juego (Lotman, 1970: 93), como elección continua del lenguaje, en suma, como producción creativa de un lector, alimentada de la semiología en tanto que teoría liberadora del significante, ya que el texto remite de un significante a otro sin clausurarse jamás, y del psicoanálisis, que puede enseñar a leer «más allá» de la palabra (Wahl, 1973: 159-162).

En definitiva, se trata de una teoría sobre lo imaginario (donde toma cuerpo el sujeto) que, en el fondo, perpetúa el lugar del sujeto en su ausencia, una teoría de las formas literarias entre la simbólica de Bachelard sobre lo imaginario - variante de la ontología-y la hipótesis de Derrida del trazo arcaico - que regresa de la metafísica a la semiología.

De esta forma, la semiótica literaria se liberará de la excesiva tiranía positivista evolucionando desde una ciencia textual a una verdadera teoría del texto (cap. V), que lo configura «como una práctica significante abierta y plural» (pág. 134).

Se produce, pues, la superación de la significación de la obra -entendida como producto cerrado-, enunciado o comunicación, y la entrada en el campo de la «significancia», es decir, de la producción, enunciación y simbolización del sentido de un significante vacío de todo contenido objetivo, que está ahí y significa en sí mismo y para sí mismo (Quesada, 1993: 129).

Lo importante de todo ello es expresado claramente por la profesora Sirvent cuando afirma que se ha producido una auténtica conversión del texto en

«[...] semiosis, no representando un mundo clausurado sino "el infinito del lenguaje": sin saber, sin razón, sin inteligencia» (pág. 143). 
El texto se configura así como una red de escrituras, independientes de su autor, que sólo clausurará cada uno de los lectores.

Ello entraña, obviamente, una carencia metodológica, que, más que una deficiencia intrínseca de los postulados hermenéuticos señalados, es la herencia inconsciente del «ontologismo» adoptado, a la vez que la plasmación consciente de la «epistemología» que la sustenta (Jiménez Ruiz, 1994b), y que debe completarse con una actitud especulativa (Ricoeur, 1960: 284) de acercamiento a este sujeto que ha perdido su unidad proyectándose en el interior de las estructuras de lo significante, puesto que la estructura (textual) está arraigada en el discurso de la ideología (Wahl, 1973: 121).

De ahí que el lenguaje sujeto - que no se da en la experiencia por no ser empírico, que determina en su relación con el objeto las condiciones formales de una experiencia que a posteriori trasladará al texto literario (Foucault, 1966: 239) - aparezca como lo otro, como un elemento epistémico no incluido en lo que se ha dado como totalidad, y que la tarea intelectual, lejos de los presupuestos positivistas, consista en asignarle el lugar que, desde un punto de vista metodológico, se le niega, transformando, para ello, la cuestión ideológica de la literatura en una cuestión puramente teórica (Sallenave et alii, 1981).

Barthes ha dado el primer paso no sólo para la recuperación sujetual mediante su dispersión, sino también para la sustitución del objeto ideológico (literatura) por un objetivo de conocimiento (teoría de las formas literarias), y Sirvent ha sabido, de manera clara y sistemática, reflejar sus presupuestos en un auténtico texto de «goce», al estilo barthesiano, que convierte al lector en un ser activo y, en definitiva, en el productor de un texto como el que, en el caso que nos ocupa, acabamos de presentar.

\section{Referencias bibliográficas}

BACHELARD, G. (1973). La filosofía del no. Buenos Aires: Amorrortu.

BAKHTINE, M. (1929). Le marxisme et la philosophie du langage. París: Minuit, 1977.

BARTHES, R. (1966). «Introducción al análisis estructural de los relatos». En Análisis estructural del relato, AAVV, 9-43. Barcelona: Ed. Buenos Aires, 1982.

- (1972). El grado cero de la escritura. Buenos Aires: Siglo XXI, 1973.

- (1973). El placer del texto. Buenos Aires: Siglo XXI, 1974. 
- (1984). El susurro del lenguaje. Más allá de la palabra y la escritura. Barcelona: Paidós, 1987.

BARTHES, R. et alii (1966). Investigaciones retóricas I y II. Barcelona: Ed. Buenos Aires, 1982.

BEORLEGUI, C. (1993). «De la objetividad (científica) a la retórica (literaria)». Letras de Deusto, 23:59, 65-86.

CHOMSKY, N. (1965). Aspectos de la teoría de la sintaxis. Madrid: Aguilar, 1970.

Crespillo, M. (1981). «Predominio lingüístico e interdisciplinariedad». Ciencias y Letras 3, 25-31.

- (1986). Historia y mito de la lingüística transformatoria. Madrid: Taurus.

DERRIDA, J. (1971). De la Grammatología. Buenos Aires: Siglo XXI.

DILTHEY, W. (1978). Teoría de la concepción del mundo. México: F.C.E.

Foucault, M. (1966). Las palabras y las cosas. Madrid: Siglo XXI, 1971.

GreIMAS, A. J. (1970). En torno al sentido. Madrid, Fragua: 1974.

HEGEL, G. (1983). «La evolución como concreción». En Introducción a la historia de la filosofía. Madrid: Sarpe.

Herrero Blanco, A. L. (1986). Signo/Texto. De gramática a retórica. Alicante: Universidad.

HJElmSlev, L. (1943). Prolegómenos a una teoría del lenguaje. Madrid: Gredos, $1974^{2}$ [1969].

JiMÉNEZ Ruiz, J. L. (1988-89). «Nuevas claves para una metahistoria simbólica de la historia de la literatura». Horizontes (Puerto Rico), 32:63 y 64, 21-36.

- (1992). «Hacia un modelo teórico que explique la estructura semántica de los significados emotivos». Estudios de Lingüística 8, 37-66.

- (1994a). «La trascendencia del sujeto lingüístico en la síntesis de una hermenéutica comprensiva del sentido». En Actas del I Congreso de Lingüistica General, Universidad de Valencia, Valencia -en prensa-.

- (1994b). «Cientificismo glotológico y humanismo lingüístico-literario: las repercusiones ontológicas de la deconstrucción sujetual». Actas del I Congreso Internacional homenaje a $R$. Barthes. Alicante: Universidad de Alicante - en prensa-.

- (1994c). Semántica sintomática. Propuestas para una hermenéutica comprensiva del sentido. Alicante: Universidad.

KRISTEVA, J. (1971). «Les épistémologies de la linguistique». Language 24, 3 13.

LACAN, J. (1966). «Función y campo de la palabra y del lenguaje en psicoanálisis». En Escritos, I-6-139. México: Siglo XXI, 1972.

LLEDÓ, E. (1970). Filosofía y lenguaje. Barcelona: Ariel.

- (1991). El silencio de la escritura. Madrid: Centro de Estudios Constitucionales.

LOTMAN, J. (1970). La estructura del texto literario. Madrid: Istmo, 1978.

MARDONES, J. M. (1991). Filosofía de las ciencias humanas y sociales. Barcelona: Anthropos.

OrTIZ OsÉs, A. (1976). Mundo, Hombre y Lenguaje crítico. Salamanca: Sígueme.

QueSADA, R. (1993). «Psicoanálisis y lenguaje». Morphé. Ciencias del lenguaje $8,125-131$.

RiCOEUR, P. (1960). La symbolique du mal. París: Aubier.

SallenaVe, D. et alii (1981). Psicoanálisis y crítica literaria. Madrid: Akal.

VERA LUjÁn, A. (1975). «Barthes o la utopía textual». Prohemio VI, 1-2, 328 y ss. 
Villena, J. A. (1992). Fundamentos del pensamiento social sobre el lenguaje. Málaga: Ágora.

- (1993). «Conformismo y ciencia del lenguaje. La ideología del neutralismo lingüístico y la posición sociolingüística». En Antiqua et nova Romania. Estudios lingüísticos y filológicos en honor de J. Mondéjar, 89-120. Granada: Universidad de Granada.

WAHL, F. (1973). ¿Qué es el estructuralismo? Filosofía. Buenos Aires: Losada, 1975.

WRIGHT, G. H. VON (1971). Explicación y comprensión. Madrid: Alianza, 1979. 